\title{
Digital Textile Printing: A New Alternative to Short-Run Textile Printing in Ghana
}

\author{
*Charles K. Ntim ${ }^{1}$, Sophia P. Ocran ${ }^{2}$, Richard Acquaye ${ }^{3}$ \\ ${ }^{1}$ Takoradi Polytechnic, Takoradi, Ghana, School of Applied Arts \\ ${ }^{2}$ Cape Coast Pobytechnic, Cape Coast, Ghana, School of Applied Science and Arts \\ ${ }^{3}$ University of Southampton, Southampton, UK, Winchester School of Art \\ *chant2kk@yahoo.com
}

\begin{abstract}
This paper is a part of a broader research into textile design technology and trends across the world and their reflection on the local Ghanaian textile industry. It places conventional manual screen printing and digital textile printing technologies side by side and discusses the various drawbacks of screen printing as against the advantages of digital textile printing to illustrate a path for a wider consideration of the latter in Ghanaian small to medium scale textile production. Short-run textile printing commissions are the main source of jobs for small to medium scale textile producers in Ghana. And manual screen printing is the main process employed by these small-scale textile printers. However, screen printing has various layers of limitations such as poor registration of the design, stains, pinholes, colour correctness, colour consistency, colour smear, dye migration, scorching, improper curing, amongst others. These layers of limitations negatively affect the overall outcome of the prints. So, as it stands now, short-run textile printing commissions are either produced manually, of course, with several inconsistencies or outsourced to China and other countries at a higher production cost. This is because, the large-scale textile factories in Ghana could print a minimum of 2400 yards due to their machine settings, calibration and running cost to make the least returns. This study highlights some of the milestones in the development of digital textiles print machines and examines some of the key aspects of their tremendous production aptitudes for short-run textile commissions. The case study research method is used because data comes largely from documentation, archival records, interviews and physical artefacts.
\end{abstract}

Keywords: Textile Design, Digital Textile Printing, Screen Printing, Short-run Prints.

\section{Introduction}

This study is an exploratory exercise into the realm of Digital Textiles Printing that primarily seeks to make a case for the consideration of technology to revolutionalise textile printing by small to medium scale textile printers in Ghana. The study seeks to give a background and trigger discourse in the area of digital textile printing and to raise awareness of its production potential. Digital textile printing is a generic term used to describe all methods of printing where a digitised image is transferred onto the substrate (Bowles and Isaacs, 2011). Broadly, there are two different types of digital printing technology namely: the electrostatic and continuous flow and drop on demand (DOD). The DOD technology has two subcategories: thermal and piezoelectric. Piezoelectric DOD inkjet technology is currently the primary method for digital printing of textiles. As the most significant advance in fabric printing technology since the invention of the silk screen, digital textile printing is bringing about a revolution in textile design. Designers are seeking inspiration from previously unexplored sources, and a new visual language for surface design is starting to evolve. According to Anand and Horrock (2004), the latest advance in textile printing can be attributed to the introduction of digital inkjet printing machines, capable of printing fabrics up to $2 \mathrm{~m}$ in width using acid, reactive or disperses dye ink set. The fabric is normally pretreated and placed in the machine in role 
form printed and then the dyes are fixed, usually by steaming in a separate machine, wash of and dried. Also, the piezoelectric and bubble jet printing systems may be used with any unused colour being diverted back to the ink reservoir and recycled. Generally four, seven-eight and up to twelve colours may be printed; the greater the colour gamut that can be printed. In general, digital inkjet printing systems are designed principally for use with textile materials, including natural fibre-based substrates such as cotton, silk and wool fabrics as well as polyesterbased fabrics, linoleum and Formica. These fabrics are specially prepared for digital printing (these fabrics are impregnated with chemicals and fixative). On some machines, the inkjets are periodically cleaned with solvent, automatically, to avoid jet blockage. Particularly with disperse dye system such printing machines may be run overnight without operator supervision, the design images being preloaded, and design change over being essentially instantaneous. Other systems are already being used for printing flags and banners and clearly have great potential for printing short production run of advanced technical textiles fabrics. Ultimately, some of reprographic printing method may be developed and research and development along these lines are continuing. Digital printing thrives on a chain of support systems. The computer is the main tool; however, the following are some other important components that ensure effective and smooth process. Digital Printer, Scanner, Joystick, Standard digital printing inks (reactive, acid, etc.).

Screen printing is a printing technique that uses a woven mesh to support an ink-blocking stencil. It is done either with flat or cylindrical screens made of silk threads, nylon, polyester, vinyon or metal. The printing paste or dye is poured on the screen and forced through its unblocked areas onto the fabric. Screen printing is also a stencil method of printmaking in which a design is imposed on a screen of polyester or other fine mesh, with blank areas coated with an impermeable substance, and ink is forced through the mesh openings of the mesh by the fill blade or squeegee and onto the printing surface during the squeegee stroke (Mazharul, 2014). The amount of yardage that could be printed at one time was limited by the length of the printing table, the speed of the operators, and the number of colours to be used. The fabric is spread flat on a padded table and fastened securely to the table. The operator(s) lay the screens in place, one at a time and forced the dye through the openings in the screen with a squeegee. This is repeated as many times as there are screens and colours for the particular design. When the fabric is completed, it is moved to racks over the printing table to dry. The amount of dye forced through the screens is controlled by the amount of pressure the printer applies so the layer of colour can be very thin or somewhat thick.

\subsection{Evolution and Development of the two Printing Techniques}

According to Mara (1979) some of the earliest applications can be found in mediaeval Japan, but it appeared in Europe in the 18th century particularly in France for stencilling patterns onto fabric and objects like shoes. In the 19th century, it remained a simple process using fabrics like organdy stretched over wooden frames as a means to hold stencils and their 'islands' in place during stencilling or printing. Only in the twentieth century did the process become mechanised, usually for printing flat posters or packaging and fabrics. It became widely used to print coloured wallpaper as a cheaper alternative to printing with wooden blocks.

Not until the 1930's did the potential of screen printing come to the attention of artists, and even in the early 1950's it remained a crude and hand done process. Faine and Blake (1989) further indicated that, gradually though the industrial applications had grown and with them better machinery but more importantly much finer and thinner films oil based inks. In the 1960's many artists found its large scale and solid bright colours perfect for the ideas of the time particularly in Pop Art. To print multiple copies of the screen design on garments in an efficient manner, amateur and professional printers usually use a screen printing press. Many companies offer simple to sophisticated printing presses. Most of these presses are manual. A few that are industrial-gradeautomatic printers still require some amount of manual labour to increase production significantly. Till date screen printing processes have remained essentially the same with very minimal sophistication. Often, it is used as a substitute for many other processes such as offset lithography. As a printing technique, it can print on almost any surface whether it is paper, card, wood, glass, plastic, leather or any fabric. In the publishing industry, it is used as a means of reproducing watercolour often in limited editions though this cannot be said to be true original prints.

Digital textile printing technology on the other hand, is a relatively new design output milestone. It started in the 1970s as a possible replacement for analogue screen printing. With the development of a dye-sublimation printer in the early 1990s, it became 
possible to print with low energy sublimation inks and high energy disperse direct inks directly onto textile media, as opposed to print dye-sublimation inks on a transfer paper and, in a separate process using a heat press, transfer it to the fabric. Behind digital printing is a range of software that is used in the design process and also in the preparation of the design for print. This only came within the remit of textiles designers once the technology for digital printing of textiles became viable in 1998. The offthe-shelf package Adobe Illustrator was first released in 1987 as a font development programme for graphic designers and later Adobe Photoshop followed in 1990. Although textile designers would have been able to use these tools, they were initially the domain of photographers and graphic designers.
A true digital style for textiles emerged ten years later (Provost, 2015).

Seiren, a Japanese company, was also a pioneer of inkjet textile printing and begun testing the viability of this technology as long as early 1980s. By 1991, they had introduced inkjet printing in textiles alongside traditional methods. Most of their early prints ended up on the custom car interior market. Fish (2005) projected that, digital printing is only a small part of the printed textile market but this will change in the future, as it will become more cost effective than other printing methods. The limitation at that moment was that the printers were very slow and used only conventional inks. Table one gives a breakdown of major digital textile printing machine developments over the last 40 years.

Table 1

Major Digital Textile Printing Machine Developments over the last 40 years

\begin{tabular}{lll}
\hline Year & Design Reference & Company \\
\hline Early 1970's & Multi Coloured Ink Jet Printing Rig & ICI/CCL(UK) \\
& for Continuous Print Head & \\
Early 1980's & Continuous Ink Jet for Textiles & Burlington (USA) \\
Late 1980's & 'Viscotec' Concept Developed & Seiren (Japan) \\
1991 & First Commercial System Trucolor & Stork (Holland) \\
& TCP - Hertz Continuous & \\
& Technology, Reactive Dye Range & \\
Mid 1990's & Bubble Jet (Thermal dod) & Canon (Japan) \\
1998 & First TX Series, Textile Printer using & Mimaki (Japan) \\
& Epson piezo dod Technology & \\
2003 & First Industrial Type Digital Printer & Reggiani (Italy) / Scitex (Israel) \\
& (Aprion Piezo Magic Print Head) & / Ciba (Swiss) \\
Mid 2000's & Single Pass Industrial Printer (Image & Osiris BV (Holland) - assets \\
& Print Head) & Purchased by Ten Cate in 2011 \\
2011 & MS LaRio High Production Digital & MS Italy \\
& Printer (KJ4B dod Piezo Heads) & \\
\hline
\end{tabular}

\section{Methodology}

The qualitative method of research was employed. Qualitative method consists of different orientations and approaches that make use of cognitive and cooperative knowledge construction that lead to data gathering and analysis strategies that generate appropriate findings (Vasilachis de Gialdino, 2011). Case study research, through reports of past studies, allows the exploration and understanding of complex issues. It can be considered a robust research method particularly when a holistic, in-depth investigation is required. Recognised as a tool in many social science studies, the role of case study method in research becomes more prominent when issues with regard to education (Gulsecen \& Kubat, 2006), sociology
(Grassel \& Schirmer, 2006) and community-based problems (Johnson, 2006), such as employment and trade example is small to medium scale textile production which is central for this study. One of the reasons for the recognition of case study as a research method is that researchers become more concerned about the limitations of quantitative methods in providing holistic and in-depth explanations of the social and behavioural problems in question. Through case study methods, a researcher can go beyond the quantitative statistical results and understand the behavioural conditions through the actor's perspective. By including both quantitative and qualitative data, case study helps explain both the process and outcome of a phenomenon through complete observation, 
reconstruction and analysis of the cases under investigation (Tellis, 1997).

A purposive sample of 82 participants were selected to effectively represent the population that consists of small scale textile producers in Greater Accra, Western, Ashanti, Central, Eastern and Volta region. The sample is made up of people who are very familiar with the rudiments of screen printing and other fabric printing methods. Formal interview and observations were used as the main data collection instruments. Simple descriptive statements were used to explain and bring out the meanings and effects of the results of data collection. Interviews are conducted in order to gain in-depth details and information about participants' opinions and views regarding knowledge on digital textile printing. Semistructured interview was employed. Sarantakos (2005), stated that semi-structured interviews stand somewhere between structured interviews and unstructured interviews, as they might share some elements of both types. There is usually an interview agenda or schedule with a plan or set of questions in a semi-structured interview; however, the agenda is mainly used as guidance for the interviewer instead of fully controlling the discussion (McQueen and Knussen, 1999). Semi-structured interviews are more flexible compared to other types of interview. They can provide more information because interviewees have the opportunity to be more elaborate in expressing their views and describing their experiences, which provide the researcher with information that may be of significant and extensive value.

\section{Results and Discussions}

As mentioned earlier in the methodology, semistructured interviews were conducted to ascertain the level of knowledge of digital textile printing amongst small to medium scale textile printers in six regions of Ghana. It came out that $70 \%$ of the respondents know of digital printing (most of these respondents have had formal education in textiles and heard about it in school). $7 \%$ of the respondents have seen some of the printers when they travel outside side the country to print commissions in China and also during their training outside the country. None of the respondents was using a digital printer at the time of the interviews. However, 26 of the respondents have T-shirt printing machines rather that operated similar to the digital textile printer except that the process involved in the use of $\mathrm{T}$-shirt printing machine is not a continuous one. When asked why they will not want to invest in a progressive technology such as digital textile printing, most of the respondents cited initial cost, technical support, operational uncertainties and other maintenance constraints as the main deterrents.

Table 2

Level of knowledge of digital textile printing amongst small to medium scale textile printers

\begin{tabular}{lcc}
\hline & $\begin{array}{l}\text { Number of } \\
\text { Respondents }\end{array}$ & $\begin{array}{c}\text { Percentage of } \\
\text { Respondents }\end{array}$ \\
\hline $\begin{array}{l}\text { I know of digital } \\
\text { textile printing } \\
\text { technology }\end{array}$ & 58 & $71 \%$ \\
$\begin{array}{l}\text { I have seen digital } \\
\text { textile printing } \\
\text { machine }\end{array}$ & 6 & $7 \%$ \\
$\begin{array}{l}\text { I don't know } \\
\text { anything about } \\
\text { digital textile } \\
\text { printing }\end{array}$ & 18 & \\
$\begin{array}{l}\text { I own digital } \\
\text { textile printing } \\
\text { machine }\end{array}$ & $02 \%$ \\
$\begin{array}{l}\text { Total number of } \\
\text { respondents }\end{array}$ & 82 & $0 \%$ \\
\hline
\end{tabular}

\subsection{Screen Printing Problems}

As indicated earlier in this study, screen printing is the main process for producing short-run textile commission by small scale textile producers in Ghana. However, screen printing has several operational challenges and various layers of faults and drawbacks. This list is endless: Choking of screens, Misfitting of the design, Stains, Conveyor stain, Blanket stain, Misprint or no print on selvedge, Design not washed out properly, Slippage on the cloth, Pinholes, Pilling of the lacquer, Placement problems, Consistency of placement, Colour correctness, Colour consistency, Colour smear, Dye migration, Scorching, Improper curing, Fibrillation or frosting, Distortion, Opacity, Poor wash fastness, Registration, Hand, Colour out and Scrimps (Mazharul, 2014). Prior to these faults and challenges, there are other issues with screen development too. Over-exposure causes loss of detail in the image area. When photo emulsion is exposed to Ultra Violet light, it polymerises or will crosslink, making it more difficult to wash out. As Ultra Violet light reaches the photo emulsion, it becomes cross-linked, rendering it difficult or impossible to wash out during the development stage. This over-exposure happens when photo emulsion stencil making when the 
exposure is longer than it should be and the Ultra Violet light begins to creep around the edges of the positive areas of your art, thus decreasing fine lines or completely obliterating them.

A cocktail of these faults is always at play at any given time when doing screen printing. This adversely affects the consistency, uniformity and excellence of screen printed fabric outcomes. Attempts at remedying theses faults over the years have not been very successful so they are managed at great expense.

\subsection{Digital Textile Printing Prospects}

Bowles and Isaacs (2011) related that, digital textile printing has some major advantages over traditional printing methods in design terms. These are: immediacy; the ability to print intricate details and millions of colours as well as the possibility of printing images on a much larger scale; being able to create customized products and engineered designs, An 'engineered' or 'placement prints, are tailored to fit the pattern pieces of a garment in such a way that, when assembled, there is a degree of continuity- the design flows unbroken around the body and image or repeated pattern is not broken by the seams. These garments are perceived as being more luxurious if a placement print were employed, as such designs are more costly and time-consuming to produce. The fact that digital tools make it easier to create engineered prints is a very exciting prospect for fashion and textile designers alike, as both digital prints and digitally-fitted garments can be brought together. Engineered prints may also be used more subtly to highlight elements such as cuffs, collars and bodices.

There are a number of computer programmes that provides a variety of drawing, painting, rendering and wide range of colour pallette. Adobe Photoshop and Adobe Illustrator have been identified as the most appropriate software for digital textile designing. However, there are other software such as Corel Draw X6 and Adobe InDesign.

Design possibilities are seemingly endless with inkjet printing. Interfering and overlaid abstract patterns that were very difficult to print with conventional printing have become fashionable thanks to inkjet printing. In conventional printing, such patterns have to be separated and rastered at great expense and then printed with a high degree of precision. This places high demands on the entire process. However, inkjet technology has become increasingly important for fashionable textile printing and this is due to more capable printers and more cost-efficient processes, inkjet printing is currently experiencing a huge boom and developing into a production process. Even though, there have been some queries with the 'flat' outcome of digital prints; the surface and tactile qualities created by traditional print methods are often lost. New ways to put back these tactile qualities into the creation of fabric are evolving through physical intervention such as over-printing and embellishment. The following processes have been identified as effective ways of dealing with the concerns above. These techniques can be combined with digital print to re-engage the designer with the cloth in other to create beautiful and innovative surfaces. Hand printing and digital printing; Screen printing and digital printing; Devore and digital printing; Foiling and flocking with digital printing; Resist dyeing and digital printing; Embroidery, embellishment and digital printing; Digital printing on conventional design.

Development in the area of digital printing has been actively progressive to meet up with operational deficiencies encountered earlier and the success rate has been very phenomenal. Figure 1 gives a recent assessment of the market which has a growth rate of $20 \%$ per year and, if estimates for digital textile production in China were included, it would be approaching the one billion square mark of digital textile production by 2016 .

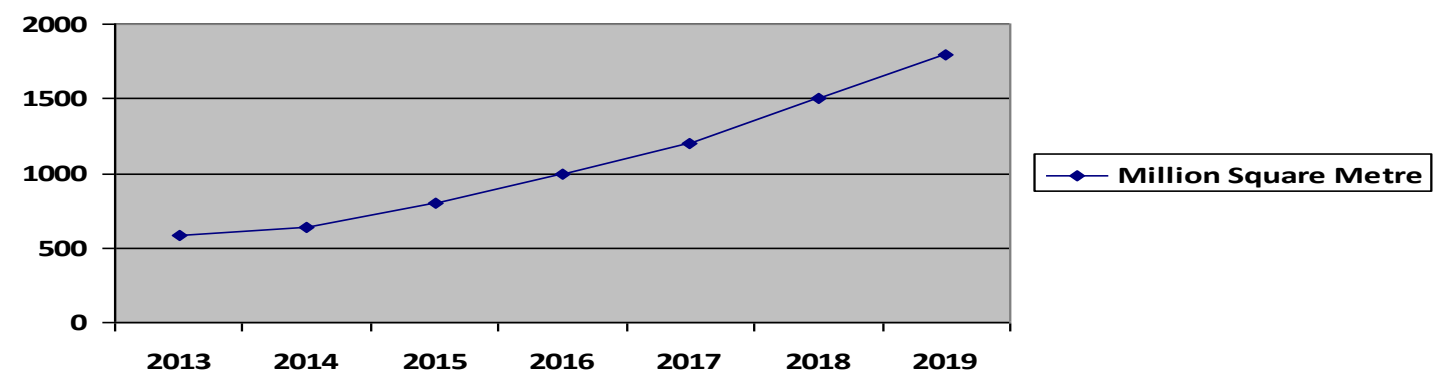

Fig. 1: Digital Textile Print Production in Millions of Square Metres and Future Forecast (Excluding Chinese Digital Production) Source: Provost Ink Jet Consulting Ltd 


\section{Conclusion}

The digital inkjet market for textiles has increased significantly since the introduction of digital textile printing machines with industrial print heads in 2011. The digital textile printing market was given a further boost in production levels with the introduction of the first 'single pass' production machine, using the Kyocera KJ4B print heads by MS of Italy in 2012, the MS LaRio machines which have production speeds up to 75 linear metres per minute. This production speed is achieved using print bars containing linear arrays of the print heads.

From the study, it is evident that digital textile printing has not made much impression in Ghana yet, except for some few companies that do some of form of T-shirt printing. Working in various design softwares such as Photoshop, Illustrator, Corel Draw and several others, designs can be recreated in simple geometric shapes, complex motifs, and unlimited colours can be blended to give a rich and exotic feel. Digital textile designs can be dynamic, exciting and reminiscent of ethnic textiles, retaining the luminosity to batik printing but with a contemporary twist. Digital textile printing can be tweaked in several forms to replace the traditional techniques of handdyed batik used in African textiles with digital media. This is because the design and printing possibilities are endless. Furthermore, there is the development of high-speed production single pass digital textile machines and this will speed up the printing cycle three times more than current speeds.

This paper has been an exposé that biased modern digital textile printing against conventional screen printing. This first in the series considers production advantages of digital printing and makes a case for its consideration by small to medium scale textiles printers in Ghana. Subsequent studies will look at acquisition, cost implication, energy needs, installation, operation and technical support, staff needs and more importantly sustainability of digital textile printing. Also with the current challenges the main textile factories are facing from pirated imported textiles, innovation in bespoke designs is the way to go and the digital textile printer will be a positive investment in this regard.

\section{References}

Bowles M. \& Isaac, C (2012). Digital Textile Design. 2nd ed. London - UK: Lawrence King Publishing. p2-56.

Faine, B. and Blake, P (1989). The New Guide to Screen Printing. United Kingdom: Headline Book Publishing.
Fish J. (2005), Designing and Printing Textiles, Ramsbury - Marlborough, UK. The Crowood Press.

Gilmour, P (1986). Ken Tyler, Master Printer, and the American Print Renaissance. USA: Hudson Hills Press Inc.

Grassel, E. and Schirmer, B., (2006). The use of volunteers to support family careers of dementia patients: results of a prospective longitudinal study investigating expectations towards and experience with training and professional support. Journal for Gerontology and Geriatrics 39 (3): 217-226 Jun.

Gulsecen, S. and Kubat, A., (2006). Teaching ICT to teacher candidates using PBL: A qualitative and quantitative evaluation. Educational Technology \& Society, 9 (2): 96-106.

Henning, R. (1994). Screen Printing: Water-based Techniques. USA: Watson-Guptill Publications Inc.

Horrocks A. H. and Anand S. C. (2004). Hand Book of Technical Textiles. Cambridge - UK. Woodhead Publishing Limited.

Mara, T. (1979). Manual of Screen Printing (The Thames \& Hudson Manuals). London: Thames \& Hudson Ltd. p47-88.

Mazharul, I. K. (2014). Faults/Defects/Problems, Causes and Remedies of Screen Printing. Available: http:/ / textilelearner.blogspot.co.uk/2013/06/faultsd efectsproblems-causes-and.html. Last accessed 2nd Feb 2015.

Mcqueen, R. and Knussen, C. (1999), Research Methods in Psychology: a practical introduction. Europe: Prentice Hall.

Provost, J. (2015). Print Head Developments - The

Key Component that Drives the Increasing Growth in the Digital Textile Printing Industry. The Colourist. Issue 1 (1), p10-12.

Sarantakos, S. (2005), Social Research Third Edition. Melbourne: Macmillan Education.

Tellis, W. (1997). Introduction to Case Study. The Qualitative Report, Volume 3, Number 2, July. (http://www.nova.edu/ssss/QR/QR32/tellis1.html).

Vasilachis de Gialdino, I. (2011). Ontological and Epistemological Foundations of Qualitative Research [85 paragraphs]. Forum Qualitative Sozialforschung / Forum: Qualitative Social Research, 10(2), Art. 30, http://nbnresolving.de/urn:nbn:de:0114-fqs0902307.

(Accessed: 14-02-2014). 